Article

\title{
An Assessment of the Wind Power Generation Potential of Built Environment Wind Turbine (BEWT) Systems in Fort Beaufort, South Africa
}

\author{
Terrence Manyeredzi * (D) and Golden Makaka \\ Physics Department, University of Fort Hare, Alice 5700, South Africa; gmakaka@ufh.ac.za \\ * Correspondence: tmanyeredzi@gmail.com
}

Received: 10 April 2018; Accepted: 24 April 2018; Published: 26 April 2018

check for updates

\begin{abstract}
The physical and economic sustainability of using built environment wind turbine (BEWT) systems depends on the wind resource potential of the candidate site. Therefore, it is crucial to carry out a wind resource assessment prior to the deployment of the BEWT. The assessment results can be used as a referral tool for predicting the performance and lifespan of the BEWT in the given built environment. To date, there is limited research output on BEWTs in South Africa, with available literature showing a bias towards utility-scale or conventional ground-based wind energy systems. This study aimed to assess the wind power generation potential of BEWT systems in Fort Beaufort using the Weibull distribution function. The results show that Fort Beaufort wind patterns can be classified as fairly good and that BEWTs can best be deployed at $15 \mathrm{~m}$ for a fairer power output as roof height wind speeds require BEWTs of very low cut-in speeds of at most $1.2 \mathrm{~ms}^{-1}$.
\end{abstract}

Keywords: distributed system; power density; renewable energy; sustainability; utility scale; wind resource

\section{Introduction}

Eskom, the custodian of South Africa's national grid, has been saddled with the government's optimistic goal of tripling the contribution by renewable energy from the current $4 \%$ of the national generating capacity to about $6000 \mathrm{MW}$ by 2020 [1]. This comes against Eskom's occasional failure to meet demand, which compels the energy regulatory authority to impose strict load shedding schedules so as to ease the pressure on the grid. The pressure in turn hampers Eskom's drive towards renewable energy use, as it is forced to focus more on meeting demand through traditional non-renewable technologies rather than promoting new renewable ones. One way of easing pressure on the national grid without the need for scheduling load shedding is promoting the use of distributed wind power systems. The major advantage of distributed wind power systems, as is the case with other distributed systems, is their proximity to end users. Distributed wind power systems can protect consumers from dearths due to technicalities associated with grid failure and transportation or capacity shortfalls, because the system can be installed within the consumer's locality. Of particular interest in this study is the built environment wind turbine (BEWT) technology that [2] identified as a developing and less mature innovation than the utility-scale or conventional ground-based distributed wind power systems.

BEWT refers to wind projects that are constructed on, in, or near buildings. One of the main factors to consider when choosing a wind turbine for deployment as a BEWT is its performance in terms of power output within the given built environment. The built environment is known to be characterised by complex wind flow patterns [3], where wind direction variations are considerable. Thus, horizontal axis wind turbines (HAWT) with their yawing system may not be capable of tracking fast and extensive variations in wind direction, thus rendering HAWTs less effective for the built 
environment [4]. On the other hand, vertical axis wind turbines (VAWTs) are more compact, and their performance is independent of wind direction; hence, VAWTs are the preferred choice for deployment as BEWTs.

The power output of a wind turbine depends on wind speed that, in turn, is a spatiotemporal variable. Therefore, it is important to carry out a wind resource assessment of the candidate site prior to deployment of the BEWT. This is crucial in assessing the physical and economic sustainability of deploying a particular wind turbine in the given environment. Carrying out a site-specific wind resource assessment gives the most reliable estimation of the wind resource potential, but this may increase installation costs and even delay deployment. Knowledge of the wind resource potential in the host region of the candidate site(s) is therefore important, as it can be used as a referral tool for predicting the performance and lifespan of the BEWT in the given built environment.

Wind speed is a random variable; hence, it can be represented statistically, with Weibull distribution being recommended by most authors due to its flexibility, simplicity, and capability to fit a wide range of wind data [5-7]. This paper is aimed at using the Weibull distribution function to assess the wind resource potential of Fort Beaufort, South Africa for the purpose of deploying BEWT systems. This may go a long way in promoting the adoption of BEWTs in South Africa and ease pressure on the national grid. South Africa is yet to adopt BEWTs, with available literature on wind power projects in the country (as is the case with other African countries) showing a bias towards wind resource potential assessment for establishing large-scale wind farms.

\section{Materials and Methods}

\subsection{Study Area}

Fort Beaufort is a town in the Amathole district of the Eastern Cape province in South Africa, whose prevailing climate is classified as steppe [8]. The district has moderate wind energy potential [9] therefore, its wind resource potential may be suitable for setting up BEWTs.

\subsection{Power Output}

The generic formula for estimating the power output $(P)$ of a wind turbine is;

$$
P=\frac{1}{2} A \rho v^{3} .
$$

Estimations of $P$ using Equation (1) are premised on the assumption that air density $(\rho)$ is independent of wind speed [6], where $A$ is the area swept by the turbine blades and $v$ is the speed of wind driving the turbine positioned at a height $h$ above the ground. Equation (1) is useful when dealing with HAWTs and less reliable for VAWTs, hence [10] formulated Equation (2) for estimating the power output of VAWTs;

$$
P(v)=P_{o} \frac{v^{3}}{v_{0}^{3}} .
$$

$P_{o}$ is the nominal power corresponding to the nominal velocity $v_{0}$. Wind speed depends on topography and altitude [11,12]; hence, wind speed measured at the weather station $\left(v_{s}\right)$ of height $H$ should be adjusted to $v$ so as to cater for differences in height and topography between the weather station and the turbine. The author of [10] came up with Equation (3) for estimating the power output of a BEWT based on the corrected wind speed;

$$
P(v)=\frac{P_{o}}{v_{o}^{3}}\left[v_{s}\left(\frac{h}{H}\right)\right]^{3} .
$$

Equation (3) was successfully used to estimate the power output of a turbine operating within the built environment at a $15-\mathrm{m}$ height, where building geometry was assumed not to influence wind 
speed. However, for a BEWT operating in/and on a building, building orientation with respect to the wind profile should be catered for when recalculating wind speed. The authors of [13] used Equation (4) to extrapolate a velocity profile from the meteorological station to the building while studying wind induced natural ventilation in residential areas:

$$
v=\kappa v_{s} h_{b}{ }^{a} .
$$

Thus, Equation (2) can be modified into Equation (5) as follows:

$$
P(v)=P_{o} \frac{\left[\kappa v_{s} h_{b}{ }^{3}\right]^{3}}{v_{o}{ }^{3}}
$$

where $h_{b}$ is the building height and $\kappa$ and $a$ are constants for the terrain conditions. Considering Fort Beaufort's peripheral zone that can be classified as suburban, the constants were assumed to be 0.35 and 0.25 for $\kappa$ and $a$, respectively.

The Psiclone power tree (Figure 1) was used as a reference BEWT.

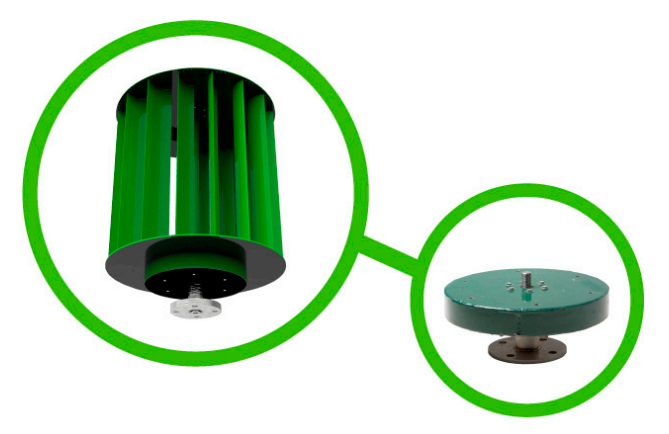

Figure 1. Diagram of the Psiclone power tree [14].

Its operational specifications are presented in Table 1.

Table 1. Specifications of the built environment wind turbine (BEWT).

\begin{tabular}{ccccc}
\hline Nominal Power Output & Nominal Rotational Speed & Cut-In Speed & Blade Total Area & Monthly Energy Yield \\
\hline $500 \mathrm{~W}$ & $400 \mathrm{rpm}$ & $2 \mathrm{~ms}^{-1}$ & $1.536 \mathrm{~m}^{2}$ & $116.67 \mathrm{kWh}$ \\
\hline
\end{tabular}

According to Eskom, an average family in South Africa uses between $500 \mathrm{kWh}$ and $750 \mathrm{kWh}$ per month [15]; therefore, the power tree can meet up to $23 \%$ of domestic energy needs when the system is operating under nominal conditions. Equation (3) was used to estimate the power output of the power tree installed within a built environment at a 15-m height, while Equation (5) was used for the BEWT installed on a rooftop assumed to be $3 \mathrm{~m}$. The power tree is too bulky for use as a BEWT inside a building; hence, the assessment was limited to the two cases mentioned.

\subsection{Wind Speed Data}

The wind speed data that was used in this study was obtained from the South African Weather Services department. The location of the weather station is given in Table 2.

Table 2. Geographical location of the Fort Beaufort weather station.

\begin{tabular}{ccc}
\hline Latitude & Longitude & Altitude \\
\hline $32^{\circ} 46^{\prime} 29^{\prime \prime} \mathrm{S}$ & $26^{\circ} 38^{\prime} 01^{\prime \prime} \mathrm{E}$ & $444 \mathrm{~m}$ \\
\hline
\end{tabular}


The data was in hourly time series format for the period of 2006-2016 and averaged into seasons. Because $v$ is a stochastic variable, the most probable wind speed $\left(v_{p r}\right)$ corresponding to the most probable power output was determined from Weibull parameters $k$ and $c$ [16] using the following formula;

$$
\begin{gathered}
v_{p r}=c\left(\frac{k-1}{k}\right)^{\frac{1}{k}}, \\
k=\left(\frac{\sigma}{\bar{v}}\right)^{-1.086} 1 \leq k \leq 10,
\end{gathered}
$$

where $\bar{v}$ is the average wind speed and $\sigma$ is the corresponding standard deviation of the measured wind speeds.

$$
c=\frac{\bar{v} k^{2.6674}}{0.184+0.816 k^{2.73855}} .
$$

The constant $k$ is the shape parameter while $c$ is the scale parameter for the Weibull distribution based on the mean wind speed standard deviation approach [5,17]. Knowledge of $v_{p r}$ is fundamental to estimating the potential of the preferred choice of a BEWT in the given environment. A large $v_{p r}$ (and hence a large power output) can support a turbine with a large cut-in speed. The probability density function, $f(v, k, c)$ is then given as follows:

$$
f(v, k, c)=\frac{k}{c}\left(\frac{v}{c}\right)^{k-1} \exp \left[-\left(\frac{v}{c}\right)^{k}\right] \text { for } v>0 \text { and } k, c>0 .
$$

The maximum wind speed corresponding to the maximum power output is obtained from $k$ and $c$ using the following formula:

$$
v_{\max }=c\left(\frac{k+2}{k}\right)^{\frac{1}{k}}
$$

\subsection{Power Density}

Wind power density $\left(P_{d}\right)$ is generally considered a better indicator of wind resource potential than wind speed [6]. It is a measure of the power available per unit square area $(A)$ swept by the wind turbine. The wind power density can be estimated using the Weibull distribution as follows:

$$
P_{d}=\frac{P(v)}{A}=\frac{1}{A} \int_{0}^{\infty} P(v) f(v, k, c) d v
$$

Thus, wind resource potential can be rated using a magnitude-based assessment categorization, as shown in Table $3[6,16]$.

Table 3. Categorization of wind resources.

\begin{tabular}{ccccc}
\hline Category & Fair & Fairly Good & Good & Very Good \\
\hline$P_{d}\left(\mathrm{Wm}^{-2}\right)$ & $<100$ & $100 \leq P_{d}<300$ & $300 \leq P_{d}<700$ & $700 \leq P_{d}$ \\
\hline
\end{tabular}

\section{Results and Discussion}

\subsection{Wind and Power Density Distribution}

Wind speed ranges from 0 to $14.8 \mathrm{~ms}^{-1}$ for the ten-year period that was considered. Table 4 summarizes the seasonal average values of wind speed and the corresponding power output for the BEWTs at 3-m and 15-m heights. 
Table 4. Seasonal average wind speed and corresponding power output for the BEWTs at 3-m and 15-m height.

\begin{tabular}{|c|c|c|c|c|c|c|c|c|}
\hline \multirow{3}{*}{ Season } & \multicolumn{4}{|c|}{ BEWT on/within the House } & \multicolumn{4}{|c|}{ BEWT at 15-m Height } \\
\hline & \multicolumn{2}{|c|}{$v\left(\mathrm{~ms}^{-1}\right)$} & \multicolumn{2}{|c|}{$P_{d}\left(\mathrm{Wm}^{-2}\right)$} & \multicolumn{2}{|c|}{$v\left(\mathrm{~ms}^{-1}\right)$} & \multicolumn{2}{|c|}{$P_{d}\left(\mathrm{Wm}^{-2}\right)$} \\
\hline & $v_{\max }$ & $v_{p r}$ & $P_{d m a x}$ & $P_{d p r}$ & $v_{\max }$ & $v_{p r}$ & $P_{d m a x}$ & $P_{d p r}$ \\
\hline Summer & 2.1 & 1.2 & 5.6 & 1.0 & 6.8 & 3.9 & 192.3 & 35.2 \\
\hline Autumn & 1.5 & 1.1 & 2.1 & 0.8 & 4.9 & 3.6 & 71.8 & 28.4 \\
\hline Winter & 1.7 & 1.4 & 2.9 & 1.7 & 5.5 & 4.5 & 99.5 & 57.6 \\
\hline Spring & 2.0 & 1.2 & 4.9 & 1.2 & 6.5 & 4.0 & 169.3 & 40.3 \\
\hline Overall & 1.8 & 1.3 & 3.6 & 1.2 & 5.9 & 4.1 & 123.1 & 41.5 \\
\hline
\end{tabular}

It can be observed from Table 4 that a BEWT deployed at $3 \mathrm{~m}$ gives a lower power density than one deployed at $15 \mathrm{~m}$, as is expected because wind speed increases with altitude. The unimodal seasonal probability densities for wind speed are presented graphically.

\subsubsection{Summer}

The wind speed distribution for summer is presented in Figure 2.

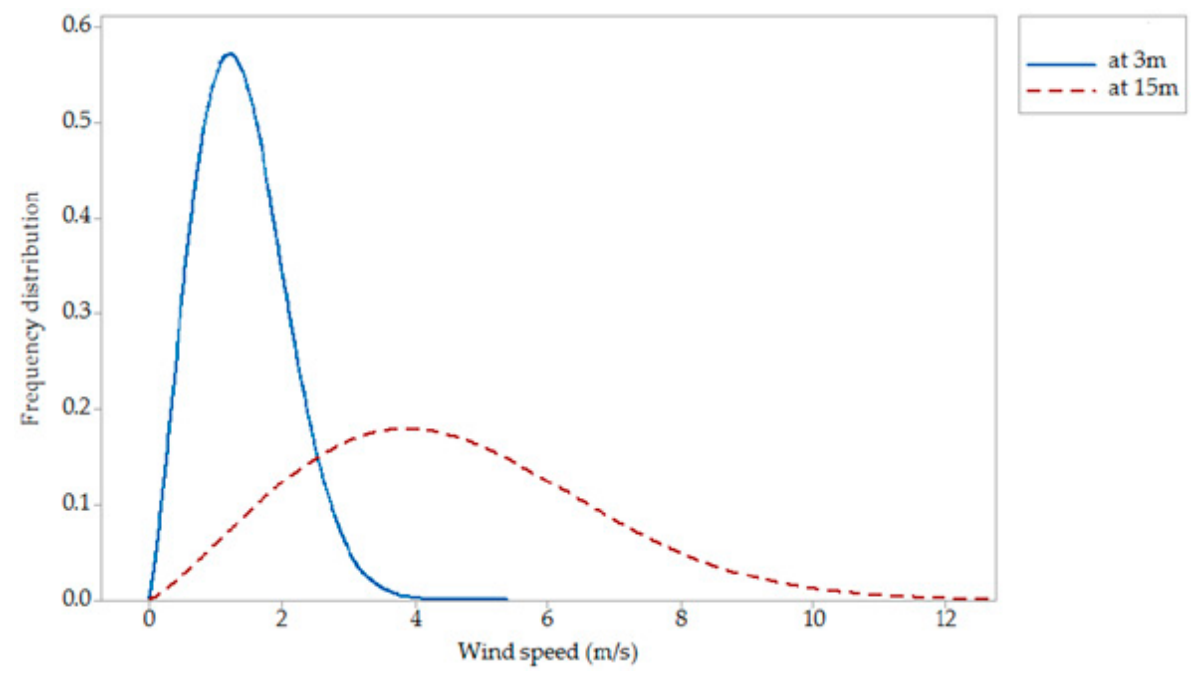

Figure 2. Weibull probability density function plot for summer in Fort Beaufort.

It can be observed from Figure 2 that the distribution is slightly skewed towards lower wind speeds; hence, the probability of having above average wind speeds is relatively low. Considering Figure 2 in conjunction with Table 4 , it can be observed that both $v_{p r}$ and $v_{\max }$ for summer are less than the cut-in speed of the BEWT at a 3-m height. This shows that the BEWT of $2 \mathrm{~ms}^{-1}$ cut-in speed cannot be supported at this height. On the other hand, both $v_{p r}$ and $v_{\max }$ at $15 \mathrm{~m}$ for summer are greater than the cut-in speed; hence, a BEWT can be supported at this height. Thus, with reference to summer, a BEWT can be deployed at $3 \mathrm{~m}$ if its cut-in speed is at most $1.2 \mathrm{~ms}^{-1}$, and such technologies are generally expensive considering the returns in terms of power output and production costs. The most probable power density at $3 \mathrm{~m}$ is $35.2 \mathrm{Wm}^{-2}$, while at $15 \mathrm{~m}$ it is $192.3 \mathrm{Wm}^{-2}$, as given in Table 4 . Using the power density categorization in Table 3, the power densities can therefore be categorized as fair and fairly good, respectively.

\subsubsection{Autumn}

The autumn wind distribution is almost symmetrical with a slight positive skew, as shown in Figure 3. 


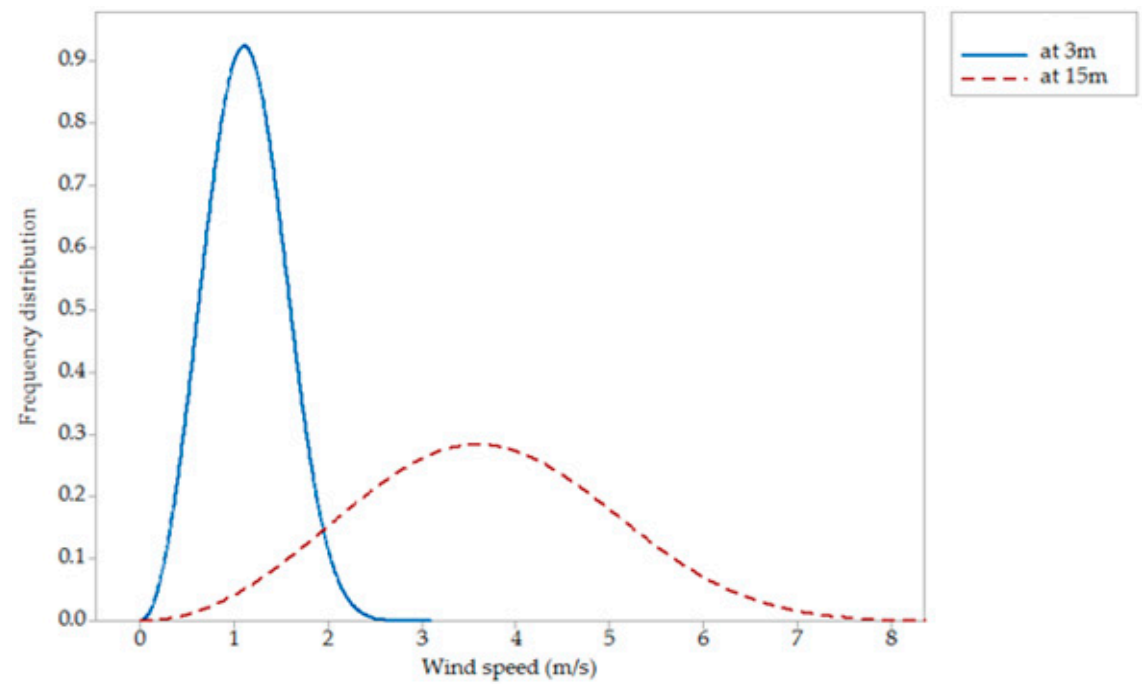

Figure 3. Weibull probability density function plot for autumn.

The modal wind speeds are $1.1 \mathrm{~ms}^{-1}$ and $3.6 \mathrm{~ms}^{-1}$ at $3-\mathrm{m}$ and $15-\mathrm{m}$ heights, respectively. The corresponding modal power densities are $0.8 \mathrm{Wm}^{-2}$ and $28.4 \mathrm{Wm}^{-2}$ at the respective heights; hence, they are both categorized as fair. The maximum power densities are $2.1 \mathrm{Wm}^{-2}$ at $3 \mathrm{~m}$ and $71.8 \mathrm{Wm}^{-2}$ at $15 \mathrm{~m}$. Therefore, wind conditions in autumn are capable of giving a fair power output for operating a BEWT.

\subsubsection{Winter}

The probability of having average or higher wind speeds in winter is relatively low, because the probability distribution for winter is again slightly skewed towards low wind speeds, as shown in Figure 4.

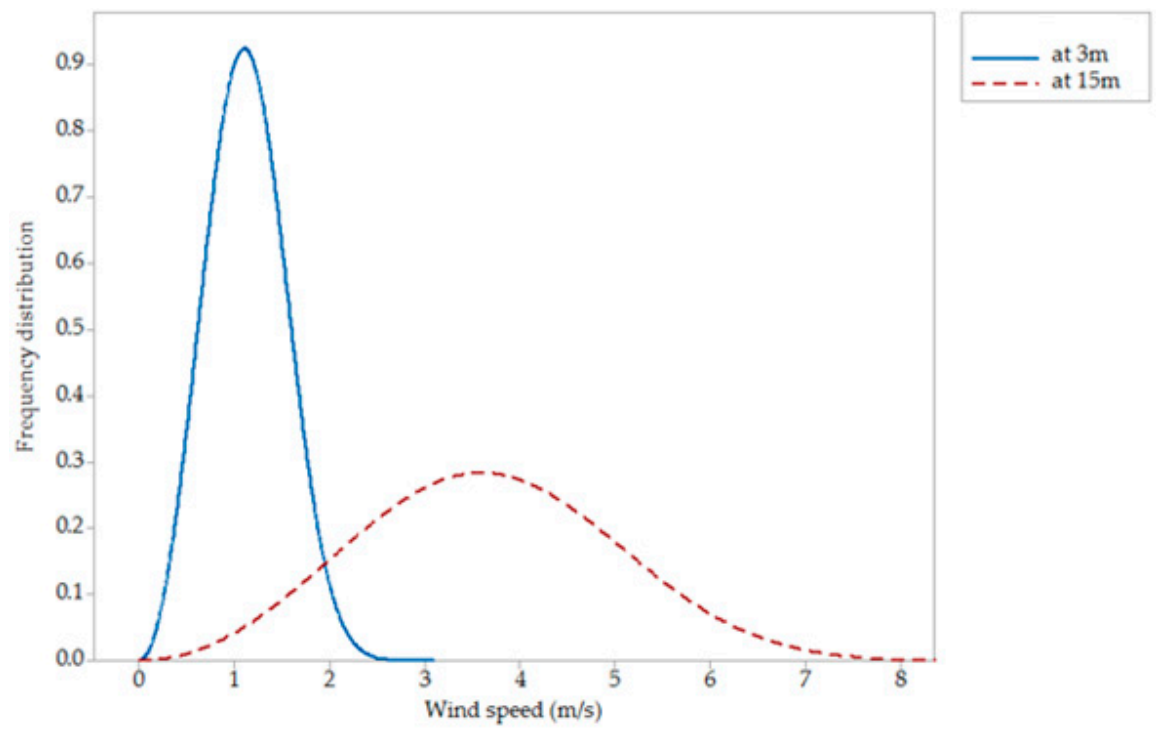

Figure 4. Weibull probability density function plot for winter.

The modal power densities are both categorized are $1.7 \mathrm{Wm}^{-2}$ and $57.6 \mathrm{Wm}^{-2}$ at the respective heights hence categorized as fair. Thus, winter wind speeds are more favorable for operating a BEWT compared to those for autumn. The corresponding maximum power densities achievable in winter are $2.9 \mathrm{Wm}^{-2}$ at $3 \mathrm{~m}$ and $99.5 \mathrm{Wm}^{-2}$ at $15 \mathrm{~m}$, both which fall under the fair category. 


\subsubsection{Spring}

The distribution for wind speeds in spring is shown in Figure 5.

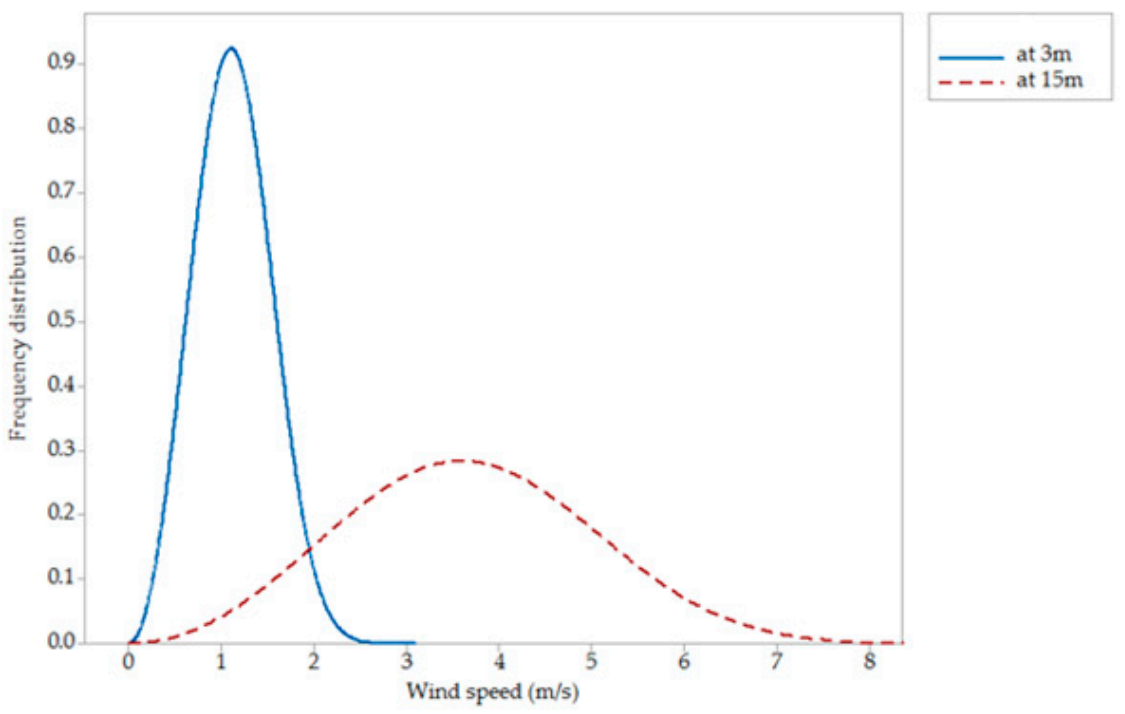

Figure 5. Weibull probability density function plot for spring.

It can be observed that the distribution is skewed towards low wind speeds. The most probable power densities are $1.2 \mathrm{Wm}^{-2}$ and $40.3 \mathrm{Wm}^{-2}$ at 3-m and 15-m heights, respectively. Thus, the wind conditions for spring can be categorized as fair for operating a BEWT, with the maximum power densities achievable being $4.9 \mathrm{Wm}^{-2}$ at $3 \mathrm{~m}$ and $169.3 \mathrm{Wm}^{-2}$ at $15 \mathrm{~m}$.

\subsubsection{Overall}

Generally, the wind speed distribution for Fort Beaufort is slightly skewed towards low wind speeds (Figure 6); hence, the probability of having below average wind speeds is slightly high.

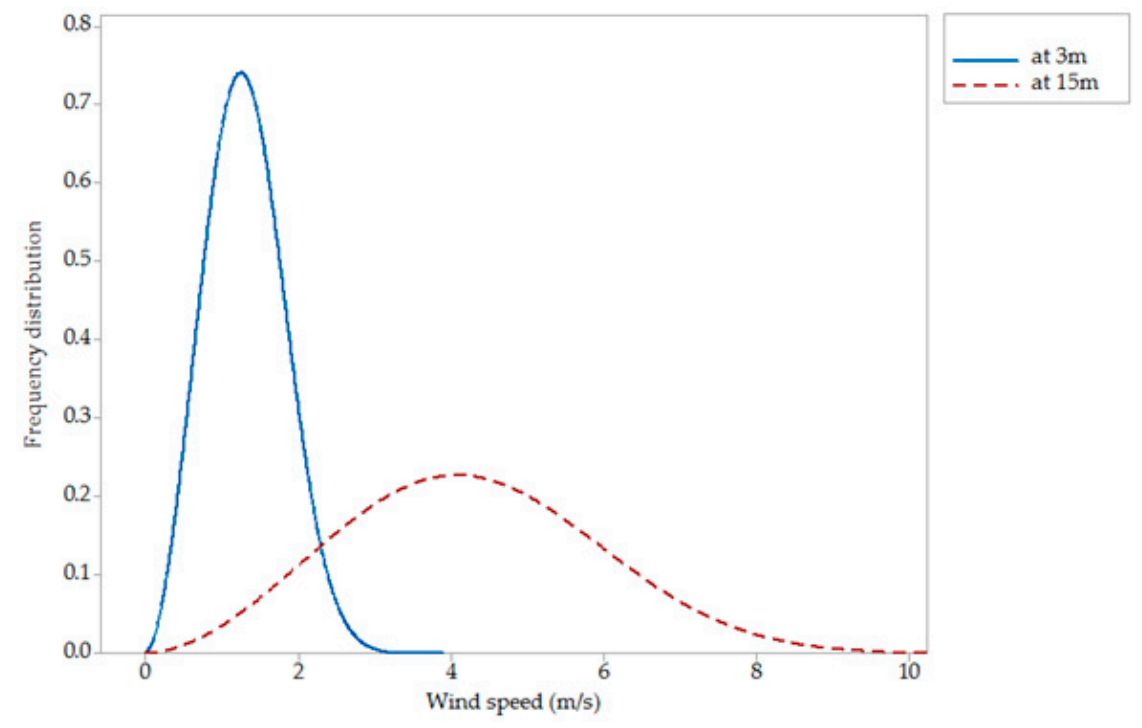

Figure 6. Weibull probability density function plot for Fort Beaufort.

The average modal power densities for Fort Beaufort are $1.2 \mathrm{Wm}^{-2}$ and $41.5 \mathrm{Wm}^{-2}$ at $3 \mathrm{~m}$ and $15 \mathrm{~m}$, respectively. Thus, wind conditions for Fort Beaufort can be categorized as fair for operating a 
BEWT, with the average maximum power densities achievable being $3.6 \mathrm{Wm}^{-2}$ at $3 \mathrm{~m}$ and $123.1 \mathrm{Wm}^{-2}$ at $15 \mathrm{~m}$.

\section{Conclusions}

The most probable seasonal power density for Fort Beaufort is in the range of $0.8 \mathrm{Wm}^{-2}$ to $1.7 \mathrm{Wm}^{-2}$ at a 3-m height. At a 15-m height, the most probable seasonal power density ranges from $28.4 \mathrm{Wm}^{-2}$ to $57.6 \mathrm{Wm}^{-2}$. Thus, seasonal wind conditions for Fort Beaufort can be categorized as fair to fairly good for operating a BEWT, with the maximum power densities achievable being $3.6 \mathrm{Wm}^{-2}$ at $3 \mathrm{~m}$ and $123.1 \mathrm{Wm}^{-2}$ at $15 \mathrm{~m}$. However, the BEWTs can best be deployed at $15 \mathrm{~m}$ for a fairer power output, as roof height wind speeds require BEWTs of very low cut-in speeds of $1.2 \mathrm{~ms}^{-1}$ that are not readily available on the market. Therefore, it is recommended to install BEWTs at $15 \mathrm{~m}$, otherwise low cut-in speed BEWTs should be used on rooftops.

Author Contributions: T.M. conceived the idea of assessing wind potential, analyzed the data as well as authoring the paper through the guidance of G.M.

Acknowledgments: The authors are grateful to the South African Weather Services for freely providing the data that was used in this study and the Govani Mbeki Research and Development Centre for financial support.

Conflicts of Interest: The authors declare no conflict of interest.

\section{References}

1. Burger, J. Unpacking Renewable Energy in Africa. How We Made It in Africa. 2017. Available online: https://www.howwemadeitinafrica.com/unpacking-renewable-energy-africa/59248/ (accessed on 10 March 2018).

2. Fields, J.; Oteri, F.; Preus, R.; Baring-Gould, I. Deployment of Wind Turbines in the Built Environment: Risks, Lessons, and Recommended Practices; NREL/TP-5000-65622; National Renewable Energy Laboratory (NREL): Golden, CO, USA, 2016.

3. Abdi, D.S.; Bitsuamlak, G.T. Wind flow simulations in idealized and real built environments with models of various level of complexity. Wind Struct. Int. J. 2012, 22, 503-524. [CrossRef]

4. Van Bussel, G.J.W.; Mertens, S.M. Small wind turbines for the built environment. In Proceedings of the Fourth European \& African Conference on Wind Engineering, Prague, Czech Republic, 11-15 July 2005; pp. 1-9.

5. Ayodele, T.; Jimoh, A.; Munda, J.; Agee, J. Statistical analysis of wind speed and wind power potential of Port Elizabeth using Weibull parameters. J. Energy S. Afr. 2012, 23, 30-38.

6. Fazelpour, F.; Soltani, N.; Rosen, M.A. Wind resource assessment and wind power potential for the city of Ardabil, Iran. Int. J. Energy Environ. Eng. 2015, 6, 431-438. [CrossRef]

7. Parajuli, A. A Statistical Analysis of Wind Speed and Power Density Based on Weibull and Rayleigh Models of Jumla, Nepal. Energy Power Eng. 2004, 8, 271-282. [CrossRef]

8. Climate-Data.org. Climate Fort Beaufort: Temperature, Climograph, Climate Table for Fort Beaufort. Available online: https:/ / en.climate-data.org/location/15812/ (accessed on 21 February 2018).

9. Masukume, P.; Makaka, G.; Tinarwo, D. An Assessment of wind energy potential of the Amatole district in the Eastern Cape Province of South Africa. In Proceedings of the 58th Annual Conference South African Institute of Physics, Richards Bay, South Africa, 8-12 July 2013; pp. 1-6.

10. Eryomin, D.I.; Yagfarova, N.I.; Turarbekov, M.K. Mathematical model to calculate the performance of low power vertical axis wind turbine. Int. J. Adv. Sci. Eng. Technol. 2016, 4, $23-25$.

11. Erdik, T.; Law, P.; Şen, Z.; Altunkaynak, A.; Erdik, T. Wind velocity vertical extrapolation by extended power law. Adv. Meteorol. 2012, 2012, 178623.

12. Maharani, Y.N.; Lee, S.; Lee, Y. Topographical Effect on Wind Speed over Various Terrains: A Case Study for Korean Peninsula. In Proceedings of the Seventh Asia-Pacific Conference on Wind Engineering, Taipei, Taiwan, 8-12 November 2009.

13. Larsen, T.S.; Heiselberg, P. Single-sided natural ventilation driven by wind pressure and temperature difference. Energy Build. 2008, 40, 1031-1040. [CrossRef]

14. Psiclone. 500w Generator. Available online: http:/ /www.psiclone.co.za/500w/ (accessed on 21 February 2018). 
15. Fripp, C. Here Is How Much You'll Pay for Eskom's Electricity from Today. htxt.africa. 2016. Available online: https: / /www.htxt.co.za/2016/04/01/here-is-how-much-youll-pay-for-electricity-from-today / (accessed on 19 April 2018).

16. Akpinar, E.K.; Akpinar, S. A statistical analysis of wind speed data used in installation of wind energy conversion systems. Energy Convers. Manag. 2005, 46, 515-532. [CrossRef]

17. Adaramola, M.S.; Agelin-Chaab, M.; Paul, S.S. Assessment of wind power generation along the coast of Ghana. Energy Convers. Manag. 2014, 77, 61-69. [CrossRef] 